\title{
Thermal analysis applied to studying the influence of ionic liquids on the vulcanization, thermal stability and damping properties of ethylene-propylene-diene rubber
}

\author{
Anna Sowińska ${ }^{1}$ (D) Magdalena Maciejewska ${ }^{1}$ (D) \\ Received: 30 October 2018/Accepted: 15 March 2019/Published online: 25 March 2019 \\ (c) The Author(s) 2019
}

\begin{abstract}
The main aspect of the research was developing new systems for activating sulfur vulcanization of ethylene-propylenediene elastomer (EPDM) with greater activity than the micrometer zinc oxide that is traditionally used. Differential scanning calorimetry (DSC) was applied to study the temperature and enthalpy of EPDM vulcanization. The range of vulcanization temperatures and the enthalpy of this process were determined. Thermogravimetric analysis was performed to characterize the effect of ILs on the thermal stability of vulcanizates. Dynamic mechanical analysis with tension deformation was used to study the influence of ILs on the loss factor ( $\tan \delta$ ) of EPDM determined as a function of temperature, which is a measure of the ability of the material to dampen vibration. DSC results indicated that ILs significantly reduced the onset temperature and enthalpy of EPDM vulcanization. The most active were alkylimidazolium chlorides, which eliminated the post-curing process. Owing to lower decomposition temperature compared to EPDM, ILs decreased the thermal stability of vulcanizates. On the other hand, ILs had no significant influence on damping properties of EPDM in the rubbery elastic region. Vulcanizates containing ILs exhibited stable dynamic properties at the temperatures of use.
\end{abstract}

Keywords Thermal analysis · Ionic liquids · Vulcanization

\section{Introduction}

Vulcanization is one of the most important processes in the rubber industry. During this process, rubber compounds change into highly elastic products—vulcanizates-by parallel subsequent physical and mainly chemical reactions. The main goal of curing is to form chemical crosslinks between rubber macromolecules, which leads to a three-dimensional network in the rubber matrix [1]. Many systems have been developed to vulcanize rubber compounds, containing sulfur, peroxides, metal oxides, phenolic resins, quinones, etc. All vulcanization systems

Anna Sowińska

anna.sowinska@edu.p.lodz.pl

Magdalena Maciejewska

magdalena.maciejewska@p.lodz.pl

1 Lodz University of Technology, Institute of Polymer and Dye Technology, Stefanowskiego Street 12/16, 90-924 Lodz, Poland provide certain benefits to the cross-linked rubber composites but also some disadvantages. The choice of the cross-linking system depends on the chemical nature of rubber and the presence of suitable functional groups in the elastomer matrix. The most popular and frequently used curatives are sulfur for unsaturated rubbers and peroxides for saturated rubbers [2].

Sulfur vulcanization is the oldest and one of the most widely used methods for the cross-linking of unsaturated rubbers [3-5]. Currently, the sulfur cross-linking system contains additional vulcanization accelerators and activators. Their presence causes the effective and rapid crosslinking of rubber with sulfur [6-8]. Activators and accelerators affect the parameters of vulcanization, such as temperature and time, as well as the safety of elastomer composite processing and the amount of sulfur needed to achieve the cross-linked structure of the vulcanizate [9]. The type of accelerator, its amount and the ratio of the accelerator to sulfur content have crucial impacts on the final properties of the rubber products, especially thermal 
and thermo-oxidative stability, and some mechanical and dynamic properties $[10,11]$. The most commonly used activator for vulcanization is metal oxide, such as zinc oxide with fatty acids (stearic, lauric, palmitic, oleic and naphthenic acid). Fatty acids solubilize the zinc and create the actual catalyst for cross-linking reactions [12, 13]. Activators are important processing additives that not only activate curing but also improve the efficiency of sulfur vulcanization systems. Almost all organic accelerators require the addition of an organic activator to achieve the desired cure rate and functional properties of composites [9]. Zinc oxide can also act as a white colorant in rubber or filler, whereas fatty acids enhance filler incorporation and its dispersion into the rubber matrix. Moreover, zinc oxide reduces the vulcanization time and improves its efficiency, as well as thermal and physical properties of the rubber compounds.

Cross-linking reactions of elastomers take place in the interface system, because sulfur particles and accelerators diffuse into the elastomer matrix and adsorb on the surface of zinc oxide, thereby activating vulcanization. From this point of view, ensuring the best contact between the curatives and the surface of the zinc oxide is crucial to achieve a high efficiency of vulcanization. This contact depends mainly on the degree of dispersion of zinc oxide and curative particles in the elastomer matrix [11].

During manufacture, use and recycling or disposal of rubber products, zinc is released. Consequently, in recent years, human activities have resulted in significantly increased amounts of zinc in the environment. According to the Environmental EU legislation, the reduction of the use of zinc oxide and zinc-containing compounds in rubber technology is required. The most crucial is European Commission Directive 2003/105/EC, in which rubber products containing more than $2.5 \% \mathrm{Zn}$ are considered highly toxic to aquatic ecosystems [14].

There are many possibilities for reducing the content of $\mathrm{ZnO}$, for example, introducing zinc in the form of reactive complexes with a higher chemical activity than $\mathrm{ZnO}$ [15]. Maciejewska and Zaborski applied new activating systems consisting of nanosized zinc oxide and ionic liquids (ILs) to reduce the content of $\mathrm{ZnO}$ and to improve the vulcanization, mechanical properties, thermal stability and resistance to thermo-oxidative aging of SBR rubber. ILs decrease vulcanization time and temperature and increase the cross-link density of rubber compounds. Moreover, using ILs allows the achievement of vulcanizates with a homogeneous distribution of zinc oxide and filler nanoparticles in the elastomer. The improvement of $\mathrm{ZnO}$ dispersion has contributed to increased vulcanization efficiency and better mechanical properties of vulcanizates $[16,17]$. ILs have increasingly been used to improve the dispersion of nanoparticles in polymers, especially in elastomers [18, 19]. ILs are defined as salts with melting point below $100{ }^{\circ} \mathrm{C}[20,21]$. ILs have been known for a long time, but in recent years, their applications have increased in polymer technology; these applications include solvents in polymerization, reagents for biomass processing [22], solvents in electrochemical devices [23, 24], absorption media for gas separations and separating agents in extractive distillation [25]. ILs can be used as solvents in different types of polymerizations, e.g., free radical polymerization [26], atom transfer radical polymerization [27] or ionic polymerization [28]. Their application in the formation of elastomer composites has become more popular, especially as vulcanization activators or accelerators, cross-linkers, dispersing agents of fillers and conductive additives [29]. Furthermore, some ILs could dissolve metal oxides. These ILs, so-called taskspecific ionic liquids (TSILs), bear a suitable functional group covalently tethered to the cationic or anionic part of IL. The functional group can coordinate to the metal ion. The concept of solubilizing metal oxides in TSILs is mainly based on the presence of acidic functional groups in the ionic liquid. Nockemann et al. [30] described a protonated betainium bis(trifluoromethylsulfonyl)imide bearing a carboxyl group, which has a selective ability to dissolve large quantities of metal oxides, e.g., ranium(VI) oxide, zinc(II) oxide, cadmium(II) oxide, mercury(II) oxide or nickel(II) oxide. The solubilizing ability for metal oxides was also observed for structural derivatives of this IL, which contain a carboxylic group attached to a positively charged nitrogen atom of imidazolium, pyridinium, pyrrolidinium, piperidinium and morpholinium cations [31]. The dissolution of metal oxides in an acid-saturated $\mathrm{IL}$, followed by selective stripping of the dissolved metal ions to an aqueous phase, was also reported by Wallens et al. [32]. The hydrophobic trihexyl(tetradecyl)phosphonium chloride saturated with a concentrated aqueous hydrochloric acid solution was used to dissolve $\mathrm{CaO}, \mathrm{NiO}, \mathrm{MnO}, \mathrm{CoO}, \mathrm{CuO}, \mathrm{ZnO}$ and $\mathrm{Fe}_{3} \mathrm{O}_{4}$. The action of ILs as catalysts of the phase transfer reactions is also known [33, 34]. Moreover, ILs should contribute to improving the solubility and/or dispersion of $\mathrm{ZnO}$ and carbon black in the elastomer, which affects the course of cross-linking and mechanical properties of elastomers. Subramaniam et al. [35] reported that thermal stability of nanocomposites also depends on the filler dispersion in the rubber matrix. Better dispersion of filler allows the achievement of higher thermal stability of the composites.

In this work, we applied different techniques of thermal analysis to study the effect of new activating systems on the temperature and enthalpy of EPDM vulcanization, thermal stability and viscoelastic properties of vulcanizates. $\mathrm{ZnO}$ was introduced into the elastomeric matrix as a mixture with a specific IL. Imidazolium ILs such as 
chlorides, tetrafluoroborates and hexafluorophosphates with the cation consisting of different length alkyl chains (from $\mathrm{C} 2$ to $\mathrm{C} 8$ ) were used. The influence of IL structure on the vulcanization and thermal behavior of EPDM was also examined.

\section{Experimental}

\section{Materials}

EPDM (Keltan 4450S) rubber containing 4.3\% ethylidene norbornene (ENB) and 52\% ethylene was obtained from Brenntag Polska (Kedzierzyn-Kozle, Poland). Its Mooney viscosity was ML1 $+4\left(125^{\circ} \mathrm{C}\right): 42$. EPDM rubber was cured using a conventional curing system containing sulfur (Siarkopol, Tarnobrzeg, Poland) in the presence of 2-mercaptobenzothiazole (MBT), tetramethylthiuram monosulfide (TMTM) and zinc dibutyldithiocarbamate (ZDBC) as accelerators (Sigma-Aldrich, Schelldorf, Germany). Microsized zinc oxide $(\mathrm{ZnO})$ with a specific surface area of $10 \mathrm{~m}^{2} \mathrm{~g}^{-1}$ (Huta Bedzin, Poland) and ILs were applied as activators in sulfur vulcanization. The ILs presented in Table 1 were provided by Ionic Liquids Technologies GmbH (Heilbronn, Germany) and Sigma Aldrich (Saint Louis, USA). Carbon black SPHERON SOA provided by Cabot Corporation (Boston, USA) was used as a filler.

\section{Preparation and characterization of EPDM rubber compounds}

EPDM compounds with compositions given in Table 2 were prepared with a laboratory two-roll mill using a twostep procedure. First, a master batch was prepared containing the filler, sulfur and vulcanization accelerators. Next, the master batch was divided into 13 equal pieces, and the mixture of $\mathrm{ZnO}$ with a proper IL was added to each of these pieces, with the exception of the reference sample, where only $\mathrm{ZnO}$ was introduced. The rubber compounds were cured at $160{ }^{\circ} \mathrm{C}$ using optimal vulcanization time $\left(t_{95 \%}\right)$ determined according to the standard PN-ISO 3417:1994 with D-RPA 3000 rheometer (MonTech, Buchen, Germany).

A DSC1 analyzer (Mettler Toledo, Greifensee, Switzerland) was employed to determine the range of EPDM vulcanization temperatures and the enthalpy. Measurements were performed in the temperature range of -100 to $250{ }^{\circ} \mathrm{C}$, with a heating rate $10^{\circ} \mathrm{C} \mathrm{min}^{-1}$. Nitrogen was used as the protective gas at the flow rate of $80 \mathrm{~mL} \mathrm{~min}^{-1}$. Prior to the measurements, the DSC analyzer was calibrated using indium and $n$-octane as standards. The DSC exothermic curves were used to evaluate the enthalpy of vulcanization $(\Delta H)$, which is directly proportional to the area under the DSC curve and was calculated by area integration software $\mathrm{STAR}^{\mathrm{e}}$ (Mettler Toledo), based on the exothermic peaks of vulcanization in the temperature range of $80-180{ }^{\circ} \mathrm{C}$. The area integrated was between the DSC curve and a baseline. The DSC curve is a graphical display of the heat flow $\phi($ or $\mathrm{d} H / \mathrm{d} t)$ that flows to

Table 1 ILs used in this study and their molar content in the rubber compounds

\begin{tabular}{llc}
\hline ILs & Molar mass/g mol ${ }^{-1}$ & Molar content/mmole \\
\hline Chlorides & & 20.5 \\
1-ethyl-3-methylimidazolium chloride $(\mathrm{EmiCl})$ & 146.6 & 174.7 \\
1-butyl-3-methylimidazolium chloride $(\mathrm{BmiCl})$ & 202.7 & 14.8 \\
1-hexyl-3-methylimidazolium chloride $(\mathrm{HmiCl})$ & 230.8 & 13.0 \\
1-methyl-3-octylimidazolium chloride $(\mathrm{OmiCl})$ & & 19.2 \\
Tetrafluoroborates & 198.0 & 13.3 \\
1-ethyl-3-methylimidazolium tetrafluoroborate $\left(\mathrm{EmiBF}_{4}\right)$ & 226.0 \\
1-butyl-3-methylimidazolium tetrafluoroborate $\left(\mathrm{BmiBF}_{4}\right)$ & 254.1 & 11.8 \\
1-hexyl-3-methylimidazolium tetrafluoroborate $\left(\mathrm{HmiBF}_{4}\right)$ & 282.1 & 10.6 \\
1-methyl-3-octylimidazolium tetrafluoroborate $\left(\mathrm{OmiBF}_{4}\right)$ & & 11.7 \\
Hexafluorophosphates & 256.1 & 10.6 \\
1-ethyl-3-methylimidazolium hexafluorophosphate $\left(\mathrm{EmiPF}_{6}\right)$ & 284.2 \\
1-butyl-3-methylimidazolium hexafluorophosphate $\left(\mathrm{BmiPF}_{6}\right)$ & 312.2 \\
1-hexyl-3-methylimidazolium hexafluorophosphate $\left(\mathrm{HmiPF}_{6}\right)$ & 340.3 \\
1-methyl-3-octylimidazolium hexafluorophosphate $\left(\mathrm{OmiPF}_{6}\right)$ & 8.6 \\
\hline
\end{tabular}


Table 2 General composition of EPDM compounds/phr

\begin{tabular}{llc}
\hline Components & Reference sample & Rubber compounds with ILs \\
\hline EPDM & 100.0 & 100.0 \\
MBT & 1.0 & 1.0 \\
TMTM & 1.0 & 1.0 \\
ZDBC & 1.5 & 1.5 \\
Sulfur & 2.5 & 2.5 \\
Carbon black & 30.0 & 30.0 \\
ZnO & 5.0 & 5.0 \\
IL & - & 3.0 \\
\hline
\end{tabular}

the sample. Enthalpy of the vulcanization $(\Delta H)$ corresponds to the integral of the exothermic peaks of vulcanization with respect to the time [Eq. (1)] [36].

$\Delta H=\int_{1}^{2} \frac{\mathrm{d} H}{\mathrm{~d} t} \mathrm{~d} t$

Thermogravimetric analysis (TG) was performed using a TGA/DSC1 analyzer (Mettler Toledo, Greifensee, Switzerland), calibrated with standards (indium, zinc). Measurements were carried out in an argon atmosphere (flow rate $60 \mathrm{~mL} \mathrm{~min}^{-1}$ ), in the temperature range of 25-600 ${ }^{\circ} \mathrm{C}$, with a heating rate of $10^{\circ} \mathrm{C} \mathrm{min}^{-1}$. Next, gas was changed into air $\left(60 \mathrm{~mL} \mathrm{~min}^{-1}\right.$.), and samples were heated to $900{ }^{\circ} \mathrm{C}$ with the same heating rate.

Dynamic mechanical measurements were performed in tension mode using a Dynamic Mechanical Analysis (DMA)/SDTA861e (Mettler Toledo, Greifensee, Switzerland) analyzer. Measurements of the dynamic module (storage modulus $E^{\prime}$ and loss modulus $E^{\prime \prime}$ ) were performed in the temperature range of -150 to $80{ }^{\circ} \mathrm{C}$ with a heating rate of $3{ }^{\circ} \mathrm{C} \mathrm{min}^{-1}$, a frequency of $1 \mathrm{~Hz}$ and a strain amplitude of $10 \mu \mathrm{m}$. The temperature of the elastomer glass transition was determined from the maximum of tan $\delta=f(T)$, where $\tan \delta$ is the loss factor and $T$ is the measurement temperature.

\section{Results and discussion}

\section{Temperature and enthalpy of EPDM vulcanization}

Using DSC analysis, we studied the effect of ILs and their structure on the temperature and enthalpy of EPDM vulcanization. This method is commonly applied to study the curing of polymers [37-39]. The results are presented in Table 3 and Figs. 1-3.
Vulcanization of the reference rubber compound (without IL) is a two-step exothermic process. The first step occurs in a temperature range of $106-185{ }^{\circ} \mathrm{C}$, with an enthalpy of $14.9 \mathrm{~J} \mathrm{~g}^{-1}$ (Fig. 1). This cross-linking process leads to the formation of sulfur bridges $\left(\mathrm{C}-\mathrm{S}_{x}-\mathrm{C}\right)$ between macromolecules and cyclic combination of sulfur [39]. At the second step, cross-linking is accompanied by some post-curing reactions such as cross-polymerization of diene units in the EPDM macromolecules and cyclization or the fragmentation of elastomer chains in the temperature range from 203 to $247{ }^{\circ} \mathrm{C}$ [40]. ILs significantly reduced the onset temperature and enthalpy of EPDM vulcanization. Alkylimidazolium chlorides were the most active, which eliminated the post-curing process. It resulted probably from the highest molar content of these ILs in the rubber compounds (Table 1). The onset vulcanization temperature of ILs-containing EPDM was approximately $12-32{ }^{\circ} \mathrm{C}$ lower than the onset vulcanization temperature of the reference rubber compound. The structure of ILs, especially the length of the alkyl chain in the cation, seems to affect their activity in the vulcanization. It should be noted that with increasing the length of alkyl chain, the molar content of IL introduced to rubber compound decreases. The onset vulcanization temperature was increased by increasing the length of the alkyl chain in the IL cation, whereas for vulcanization enthalpy, the inverse relationship was observed. Therefore, it was concluded that the activity of ILs in the vulcanization process increases with decreasing the molar mass, so with increasing their molar content in the rubber compound. The anion of ILs did not significantly influence the onset vulcanization temperature, while the enthalpy of this process was the highest for rubber compounds with hexafluorophosphates (Fig. 3). DSC analysis of rubber compounds proved that ILs can increase the efficiency of vulcanization, making it possible to reduce the temperature of this process, which is important from the economic point of view. The results obtained also confirmed that physical properties of ILs and consequently their activity in different processes can be tailored for potential application by varying the structure of the cation.

\section{Thermal stability of EPDM vulcanizates}

The structure of ILs is commonly known to affect their thermal properties such as melting and freezing points or decomposition temperature [41]. On the other hand, thermal stability of additives can influence the thermal behavior of elastomeric composites. Thermal stability is very important for the technological application of rubber products. From this point of view, ILs, which are used to improve the dispersion of other ingredients in the elastomer matrix, should not significantly affect this property. Therefore, TG analysis was performed to characterize the 
Table 3 Temperature and enthalpy of EPDM

vulcanization measured by DSC

\begin{tabular}{lcc}
\hline EPDM compounds & Vulcanization temperatures $/{ }^{\circ} \mathrm{C}$ & Vulcanization enthalpy $/ \mathrm{J} \mathrm{g}^{-1}$ \\
\hline $\mathrm{ZnO}$ & $106-185$ & 14.9 \\
Chlorides & $74-181$ & 10.5 \\
$\mathrm{EmiCl}$ & $86-182$ & 9.2 \\
$\mathrm{BmiCl}$ & $87-179$ & 4.5 \\
$\mathrm{HmiCl}$ & $94-181$ & 4.7 \\
OmiCl & & \\
Tetrafluoroborates & $84-177$ & 9.6 \\
EmiBF$_{4}$ & $88-180$ & 7.0 \\
$\mathrm{BmiBF}_{4}$ & $88-180$ & 7.0 \\
$\mathrm{HmiBF}_{4}$ & $93-176$ & 4.7 \\
$\mathrm{OmiBF}_{4}$ & & \\
$\mathrm{Hexafluorophosphates}_{\mathrm{EmiPF}_{6}}$ & $85-178$ & 12.0 \\
$\mathrm{BmiPF}_{6}$ & $89-180$ & 8.2 \\
$\mathrm{HmiPF}_{6}$ & $88-182$ & 8.5 \\
OmiPF $_{6}$ & $92-176$ & 6.4 \\
\hline
\end{tabular}

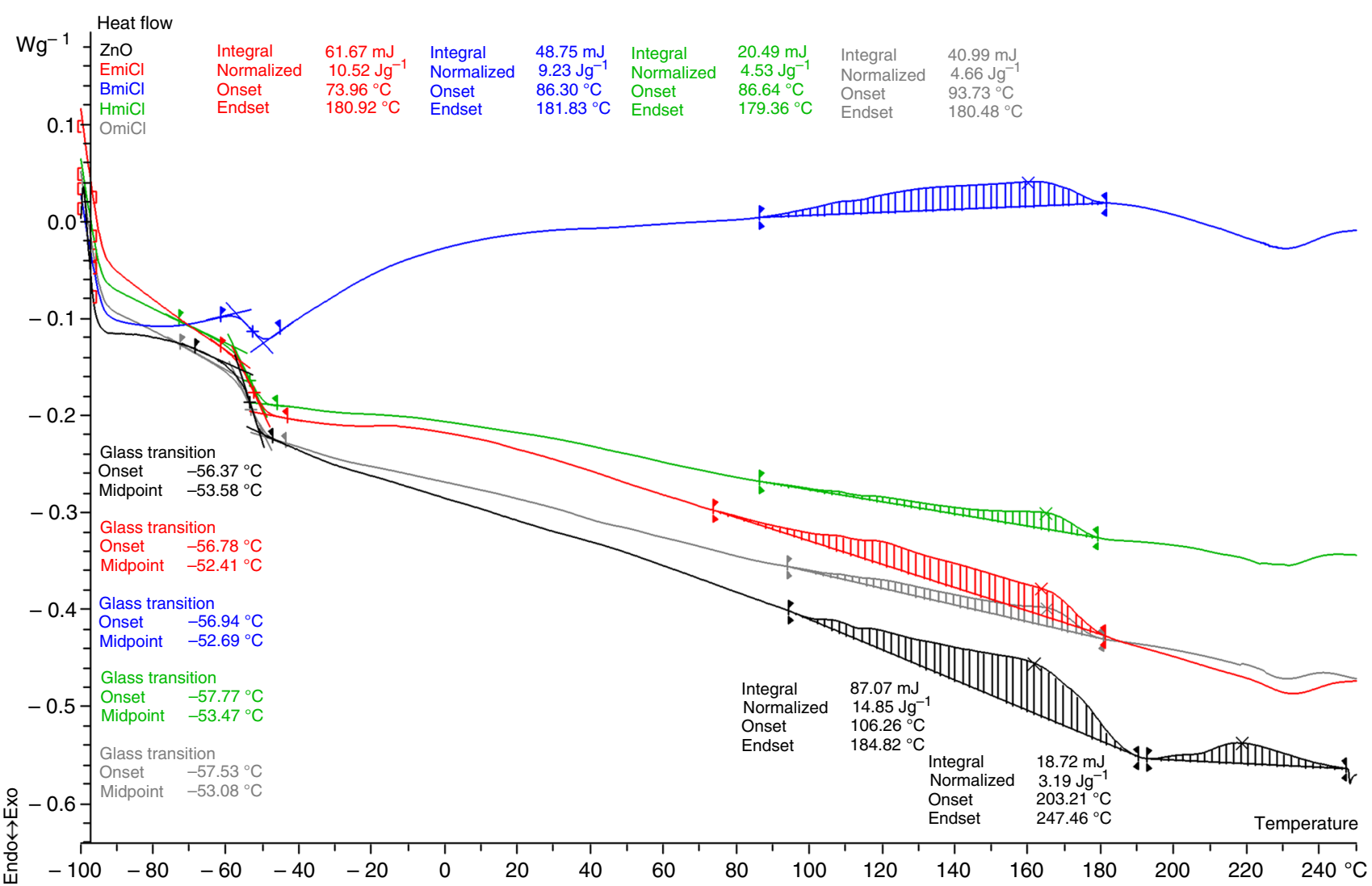

Fig. 1 DSC curves of vulcanization for EPDM containing alkylimidazolium chlorides

effect of ILs on the thermal stability of EPDM vulcanizates. The temperature of $5 \%$ mass loss of sample $\left(T_{5 \%}\right)$ was taken as the beginning of decomposition. Additionally, $T_{50 \%}$ was determined as the temperature at which mainly pyrolysis of elastomer occurs. The results are given in
Table 4 and Figs. 4-6. TG was also applied to check the thermal stability of pure ILs (Table 5).

Thermal decomposition of EPDM involves two steps. The first step is pyrolysis of the elastomer in an argon atmosphere accompanied by thermal decomposition of 


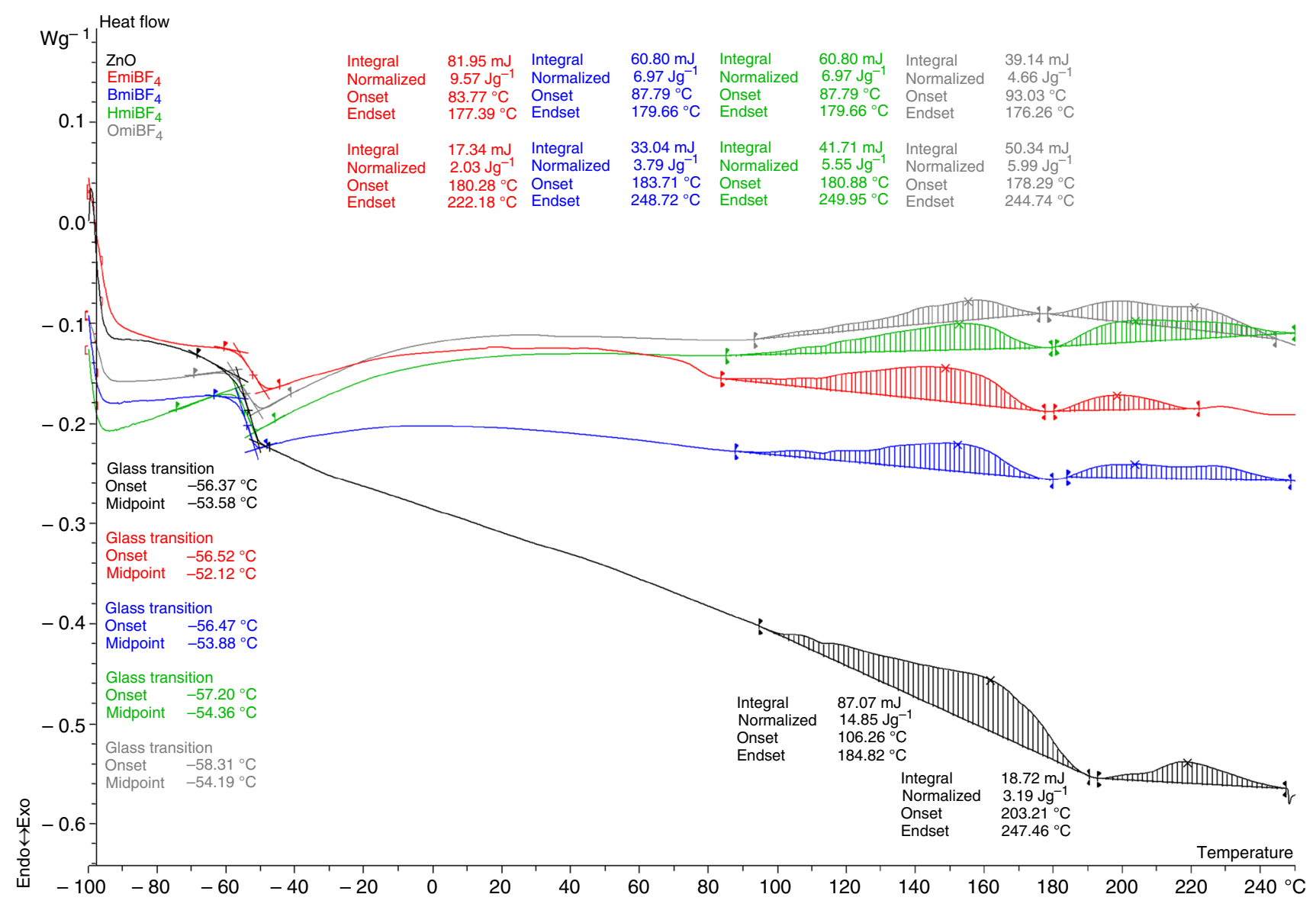

Fig. 2 DSC curves of vulcanization for EPDM containing alkylimidazolium tetrafluoroborates

organic compounds such as vulcanization accelerators and ILs. Therefore, the mass losses obtained in the temperature range of $25-600{ }^{\circ} \mathrm{C}$ correspond to the content of EPDM and organic ingredients in rubber compounds and are higher for vulcanizates containing ILs. After changing the gas to air, burning of residue after elastomer pyrolysis and $\mathrm{CB}$ used as a filler occurred at a temperature above $600{ }^{\circ} \mathrm{C}$. Thus, the mass losses in the temperature range of $600-900{ }^{\circ} \mathrm{C}$ correspond to the content of $\mathrm{CB}$ and are quite comparable for all vulcanizates due to the same content of the filler. TG and DTG curves presented in Figs. 4-6 almost overlapped for studied vulcanizates. However, regarding $T_{5 \%}$ temperature, the effect of ILs and their structure on the thermal stability of EPDM is clearly noticeable. $T_{5 \%}$ determined for the reference vulcanizate without IL was approximately $431{ }^{\circ} \mathrm{C}$. ILs reduced the onset decomposition temperature of EPDM. The anion of the IL seems to influence the thermal stability of vulcanizates considerably. The largest reduction of $T_{5 \%}$ temperature (by more than $60{ }^{\circ} \mathrm{C}$ ) was achieved for EPDM containing alkylimidazolium chlorides, whereas the smallest reduction of $T_{5 \%}$ temperature was achieved for hexafluorophosphates (by $20-30{ }^{\circ} \mathrm{C}$ ). $T_{5 \%}$ determined for vulcanizates with alkylimidazolium tetrafluoroborates was approximately $40{ }^{\circ} \mathrm{C}$ lower compared to the reference sample. ILs did not affect the $T_{50 \%}$ or the temperature of elastomer pyrolysis. Therefore, it was concluded that the decrease in $T_{5 \%}$ temperature of vulcanizates was due to lower stability of ILs, the decomposition of which preceded the pyrolysis of the elastomer. To confirm this conclusion, thermal stability of selected pure ILs with different anions and 1-ethyl-3-methylimidazolium or 1-hexyl-3-methylimidazolium cation was studied. The results obtained correspond to the effect of ILs on $T_{5 \%}$ temperature of vulcanizates. The lowest thermal stability was exhibited by the chlorides, which started decomposition at temperatures above $200{ }^{\circ} \mathrm{C}$ (Table 5). These ILs caused the greatest reduction of $T_{5 \%}$ temperature for vulcanizates. Moreover, in addition to the lowest thermal stability of alkylimidazolium chlorides, their molar contents in the rubber compounds were the highest, which contributed to the reduction in the $T_{5 \%}$ temperature of vulcanizates. Tetrafluoroborates and hexafluorophosphates showed considerably higher thermal stability than chlorides, but $T_{5 \%}$ 


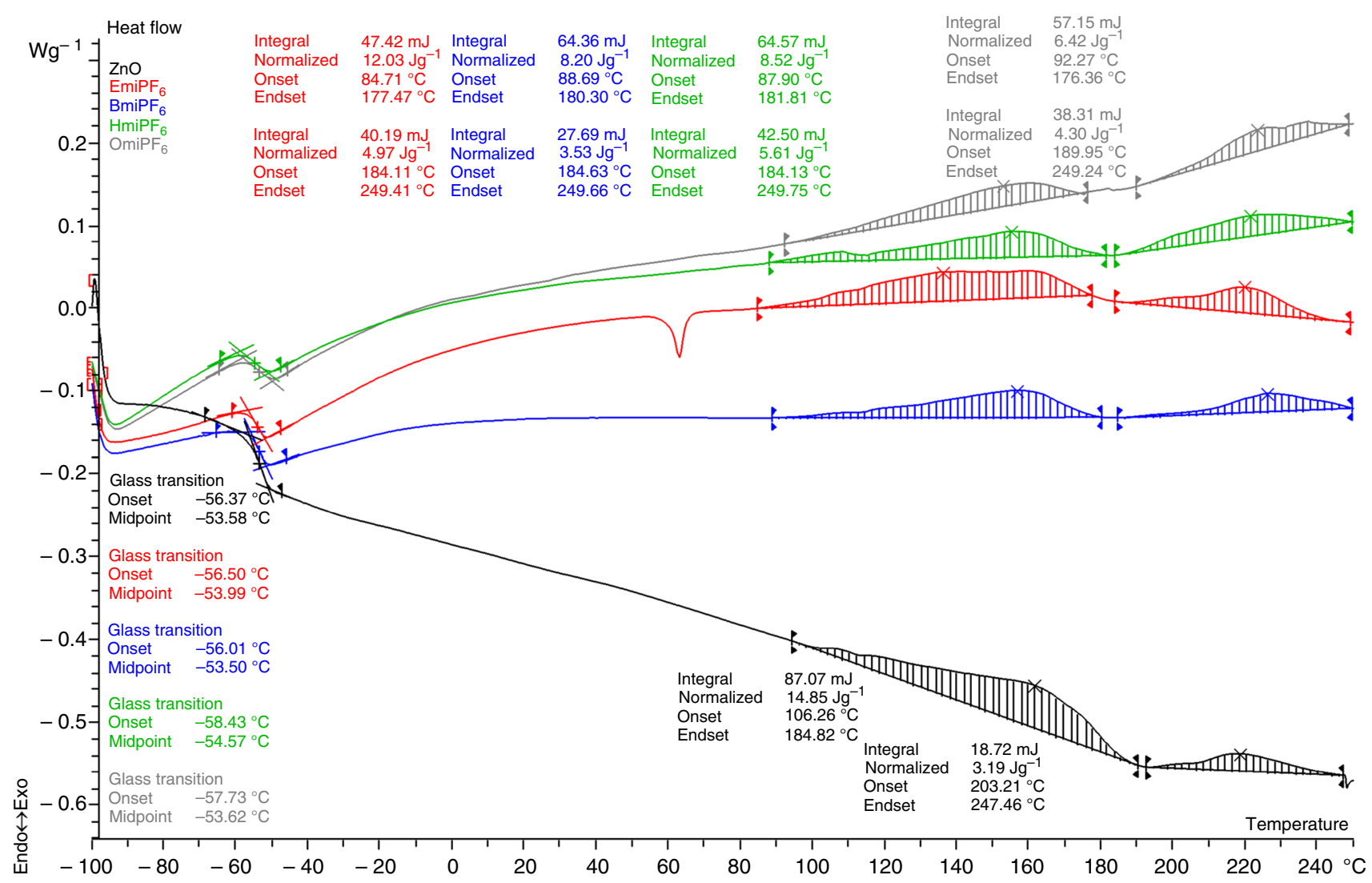

Fig. 3 DSC curves of vulcanization for EPDM containing alkylimidazolium hexafluorophosphates

Fig. 4 TG and DTG curves for EPDM vulcanizates containing alkylimidazolium chlorides
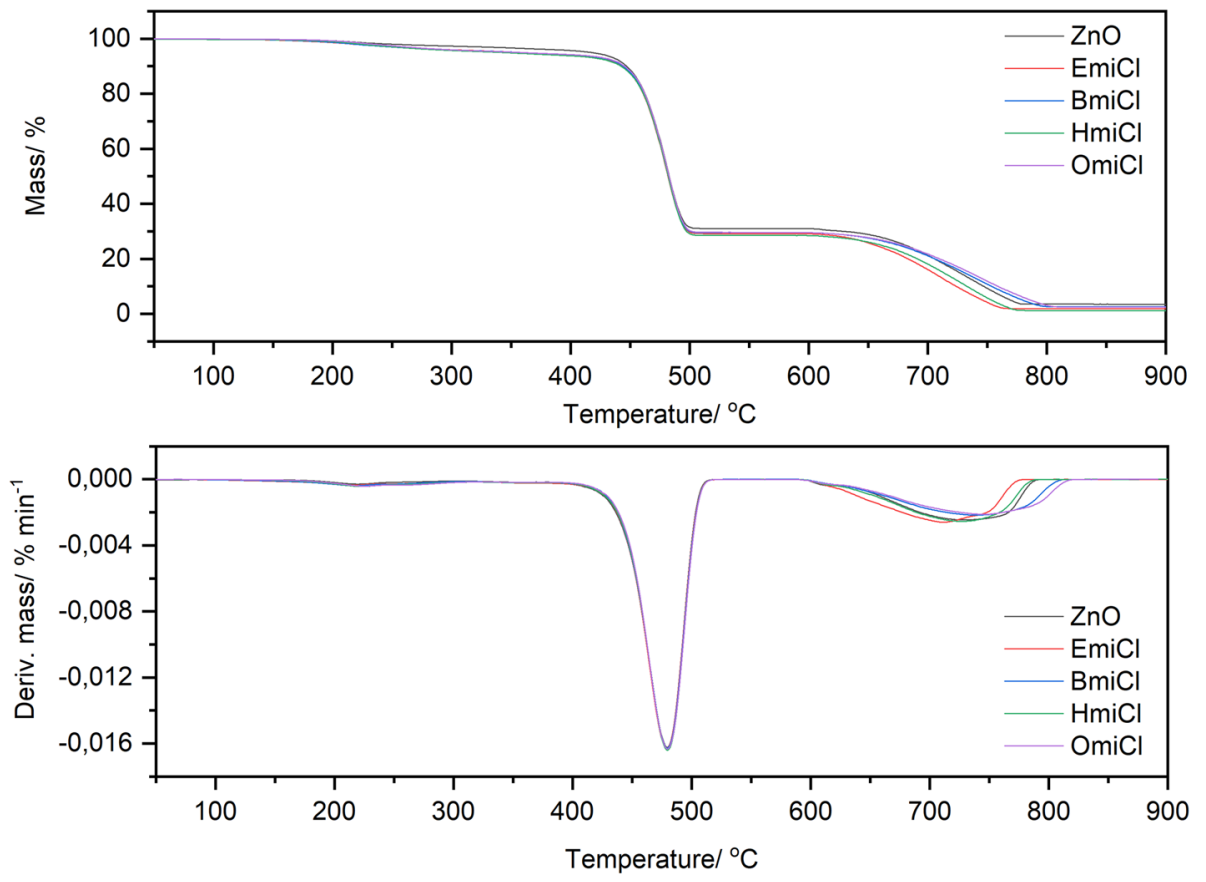

temperatures determined for these ILs were also lower than $T_{5 \%}$ of the reference EPDM vulcanizate without IL (above $380{ }^{\circ} \mathrm{C}$ for ILs with Emi-cation and above $400{ }^{\circ} \mathrm{C}$ for ILs with Hmi-cation). Onset decomposition temperature of pure ILs increased with the length of the alkyl chain in the imidazolium cation, whereas for $T_{50 \%}$, we observed an 
Fig. 5 TG and DTG curves for EPDM vulcanizates containing alkylimidazolium tetrafluoroborates
Fig. 6 TG and DTG curves for EPDM vulcanizates containing alkylimidazolium hexafluorophosphates
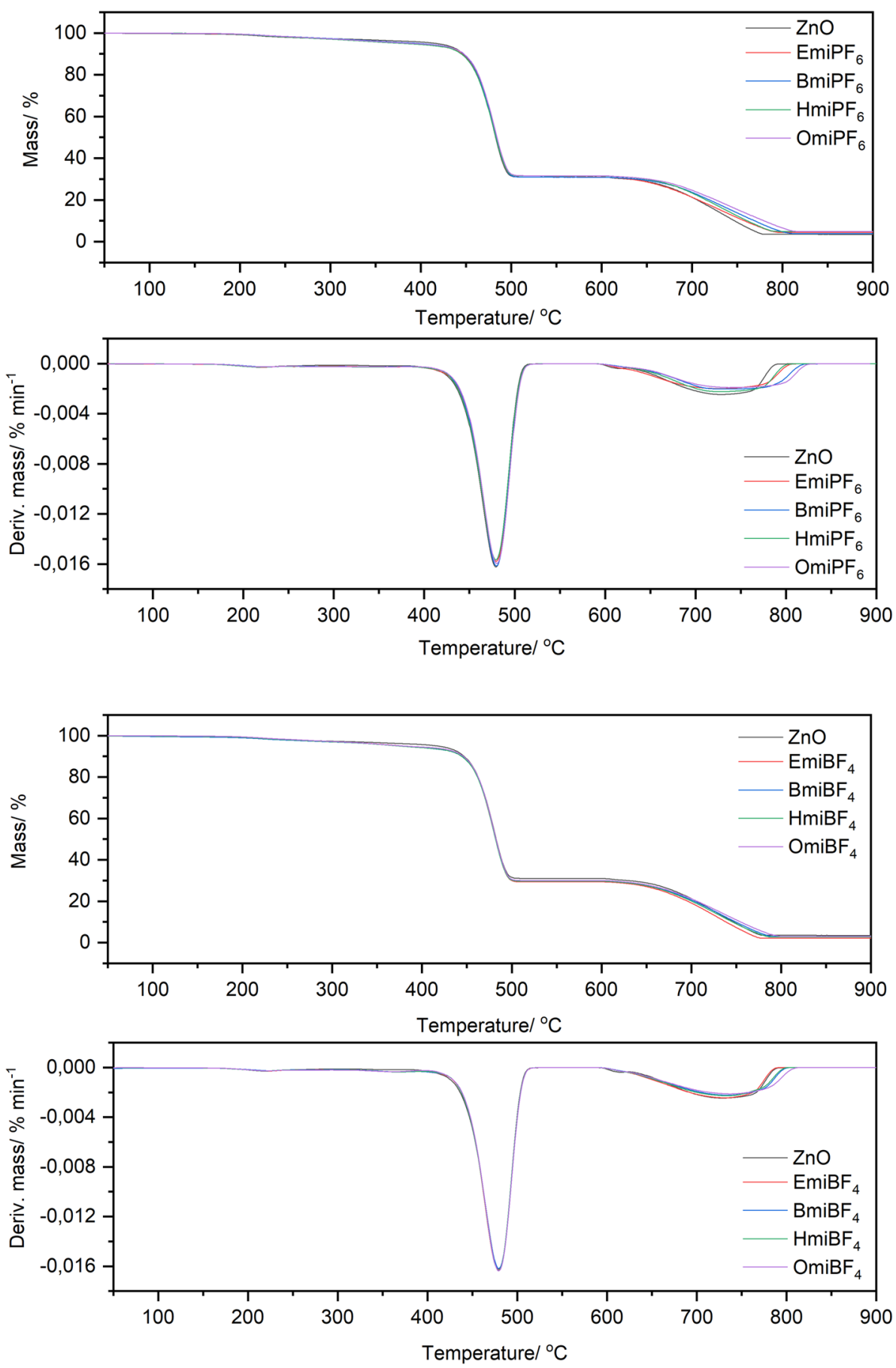

inverse relationship, independent of the IL anion. Similar behavior was reported by $\mathrm{Ngo}$ and coworkers for other alkylimidazolium ILs with different anions [41]. Considering the working temperatures of EPDM-based products, the reduction of the $T_{5 \%}$ temperature by $20-40{ }^{\circ} \mathrm{C}$ should not affect the potential applications of this type of material.

\section{Mechanical properties of vulcanizates under dynamic conditions}

Dynamic mechanical properties are very important for technological applications of EPDM compounds. Rubber products often work under the conditions of variable stress and strain. However, regardless of the working conditions, their mechanical properties should be stable during use. No less important is the ability of rubber composites to 
Table 4 Decomposition temperatures at $5 \% / T_{5 \%}, 50 \% /$ $T_{50 \%}$ and total mass loss during decomposition of EPDM vulcanizates

\begin{tabular}{lllll}
\hline EPDM vulcanizates & $T_{5 \%} /{ }^{\circ} \mathrm{C}$ & $T_{50 \%} /{ }^{\circ} \mathrm{C}$ & $\Delta m\left(25-600{ }^{\circ} \mathrm{C}\right) / \%$ & $\Delta m\left(600-900{ }^{\circ} \mathrm{C}\right) / \%$ \\
\hline ZnO & 431 & 499 & 67.9 & 27.5 \\
Chlorides & & & & \\
EmiCl & 369 & 498 & 70.9 & 27.2 \\
$\mathrm{BmiCl}$ & 370 & 498 & 70.4 & 26.9 \\
$\mathrm{HmiCl}$ & 364 & 498 & 71.5 & 27.0 \\
OmiCl & 370 & 498 & 70.3 & 27.1 \\
Tetrafluoroborates & & & & \\
EmiBF & & 498 & 70.0 & 26.9 \\
$\mathrm{BmiBF}_{4}$ & 390 & 498 & 70.4 & 27.2 \\
$\mathrm{HmiBF}_{4}$ & 393 & 498 & 70.2 & 27.0 \\
OmiBF $_{4}$ & 388 & 498 & 70.0 & \\
$\mathrm{Hexafluorophosphates}$ & 393 & & & 26.5 \\
EmiPF $_{6}$ & 402 & 499 & 69.0 & 27.0 \\
BmiPF $_{6}$ & 413 & 499 & 69.0 & 26.6 \\
$\mathrm{HmiPF}_{6}$ & 401 & 499 & 68.5 & 26.7 \\
OmiPF $_{6}$ & 404 & 500 & 68.4 & \\
\hline
\end{tabular}

dampen vibrations. Therefore, DMA analysis was employed to determine the influence of ILs on the viscoelastic properties of EPDM composites, based on the storage modulus $E^{\prime}$ and mechanical loss factor $(\tan \delta$ ), which is a measure of the ability of the material to dampen vibration. The storage modulus is proportional to the energy retained during deformation; moreover, the storage modulus characterizes the elastic properties of the material [42]. DMA measurements were performed as a function of temperature to study the influence of ILs on the glass transition of EPDM and its properties in the rubbery elastic region. The results are presented in Figs. 7-9 and Table 6.

The storage modulus of EPDM composites decreases with increasing the temperature (Figs. 7-9). The main loss of the storage modulus was observed in the temperature range from -80 to $-30{ }^{\circ} \mathrm{C}$ due to the glass transition of the elastomer. After transition to the rubbery elastic region, the storage modulus of vulcanizates was almost constant in the measured temperature range, which indicates very stable dynamic properties of this material. ILs influenced the storage modulus of EPDM in a glassy state, but in the rubbery elastic region, their effect was much less pronounced. Regarding the structure of ILs, the more important influence seems to be the type of anion. Vulcanizates containing alkylimidazolium chlorides showed, in the glassy state, a storage modulus slightly lower or comparable to the reference sample. On the other hand, vulcanizates containing ILs with $\mathrm{BF}_{4}$ and $\mathrm{PF}_{6}$ anions exhibited approximately 100-300 MPa higher storage modulus than the reference vulcanizate in the glassy state. The variant influence of ILs with different structures on the EPDM storage modulus may result from their different reactivities to the filler or elastomer matrix and from their different molar contents in the rubber compounds. High reactivity of ILs to the filler results from their strong interactions and may prevent the particles of the filler from agglomeration, resulting in the improvement of the dispersion of the filler in the elastomer matrix. ILs may behave like a coupling agent between rubber and CB filler. This phenomenon affects the mechanical properties of vulcanizates under both static and dynamic conditions. The effect of IL structure on the interaction with the filler and, as a consequence, on the dispersion of the filler in the elastomer and the dynamic properties of elastomeric composites was confirmed for multiwalled carbon nanotubes [43], so the same influence could be expected for the carbon black used in this study. According to Das et al., ILs interacted with the $\pi$-electrons of the CNTs due to delocalization of the $\pi$ electrons in the imidazolium cation of ionic liquid. $\mathrm{CB}$ with the surface of graphitic structures, which, as with CNTs, possess delocalized $\pi$-electrons that can interact with ILs in a manner similar to CNTs. The attractive interactions between the cation of the IL and the $\pi$-electrons on the $\mathrm{CB}$ surface were also postulated to improve the compatibility between the silicon rubber and the $\mathrm{CB}$ and, consequently, the extent of the dispersion of the $\mathrm{CB}$ particles in the elastomer [44].

Only one phase transition occurred in the $\tan \delta$ curves of all vulcanizates in the measured temperature range. This phase transition was the glass transition of EPDM with $T_{\mathrm{g}}$ corresponding to the temperature of the maximum $\tan \delta$ peak. ILs did not significantly affect the $T_{\mathrm{g}}$ of EPDM, which was $-59{ }^{\circ} \mathrm{C}$ for the reference vulcanizate and in the range from -59 to $-62{ }^{\circ} \mathrm{C}$ for vulcanizates with ILs (Table 6). On the other hand, the influence of ILs on the values of $\tan \delta$ at $T_{\mathrm{g}}$ depends on their structures, mainly on 
Fig. 7 Loss factor $\tan \delta$ and $\log$ of storage modulus $E^{\prime}$ versus temperature for EPDM vulcanizates containing alkylimidazolium chlorides
Fig. 8 Loss factor $\tan \delta$ and $\log$ of storage modulus $E^{\prime}$ versus temperature for EPDM containing alkylimidazolium tetrafluoroborates
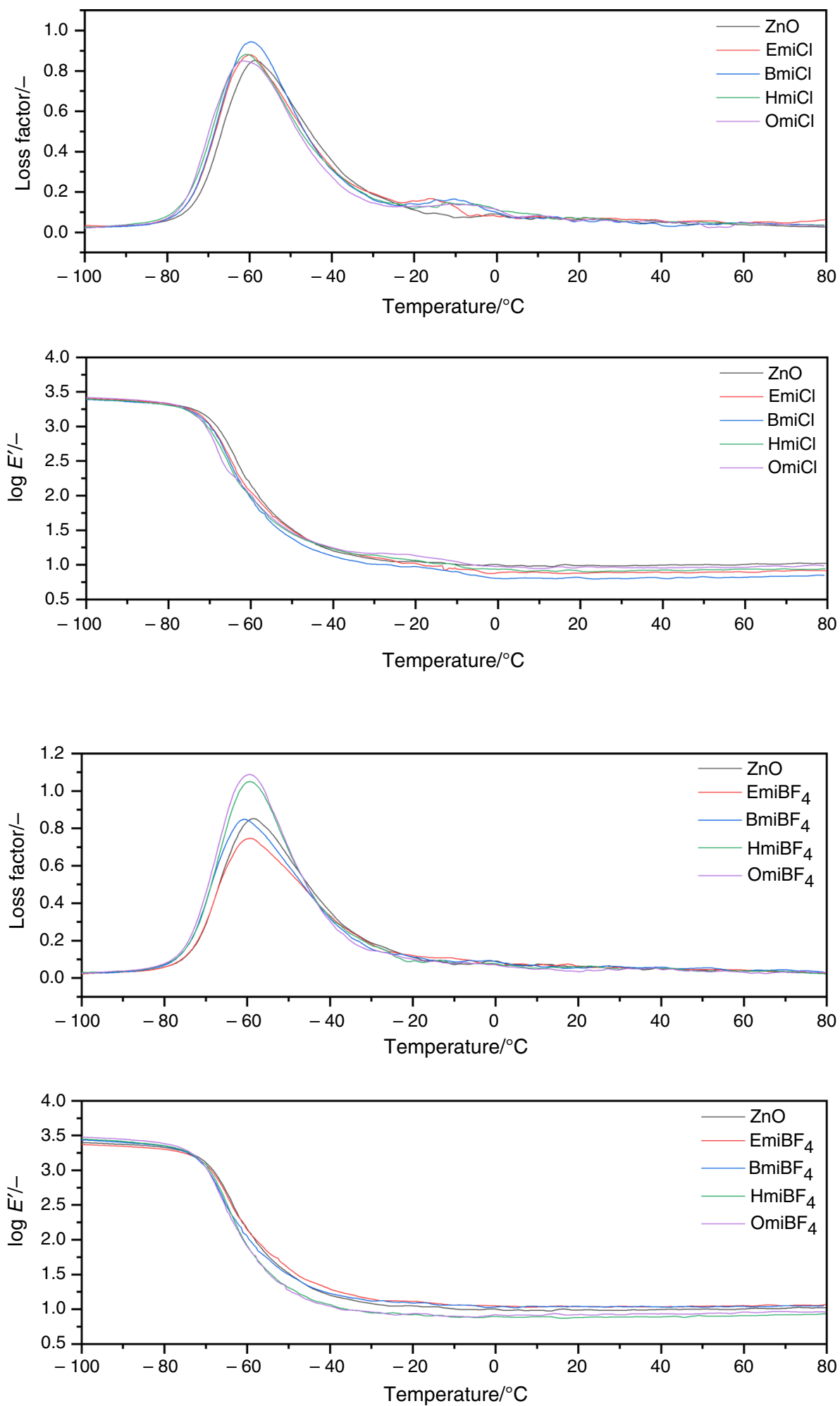

the type of anion. Alkylimidazolium chlorides did not influence the loss factor at $T_{\mathrm{g}}$ compared to the reference vulcanizate. The only exception was $\mathrm{BmiCl}$, which slightly increased this parameter. The highest loss factor at $T_{\mathrm{g}}$ exhibited vulcanizates containing hexafluorophosphates and long-chain tetrafluoroborates. The loss factor determined for these vulcanizates was close to 1. ILs did not significantly affect the loss factor, so damping properties of EPDM in the rubbery elastic region. In addition, the vulcanizates exhibited stable dynamic properties at the 
Fig. 9 Loss factor $\tan \delta$ and $\log$ of storage modulus $E^{\prime}$ versus temperature for EPDM vulcanizates containing alkylimidazolium hexafluorophosphates
Table 5 Decomposition temperatures at $5 \% / T_{5 \%}$ and $50 \% / T_{50 \%}$ mass loss of pure ILs

\begin{tabular}{lll}
\hline ILs & $T_{5 \%} /{ }^{\circ} \mathrm{C}$ & $T_{50 \%}{ }^{\circ} \mathrm{C}$ \\
\hline $\mathrm{EmiCl}$ & 204 & 305 \\
$\mathrm{HmiCl}$ & 252 & 301 \\
$\mathrm{EmiBF}_{4}$ & 381 & 498 \\
$\mathrm{HmiBF}_{4}$ & 421 & 478 \\
$\mathrm{EmiPF}_{6}$ & 389 & 504 \\
$\mathrm{HmiPF}_{6}$ & 402 & 488
\end{tabular}

temperatures of use, since the loss factor did not change considerably in the temperature range of $25-80{ }^{\circ} \mathrm{C}$ (Table 6, Figs. 7-9).

\section{Conclusions}

New activating systems consisting of $\mathrm{ZnO}$ and ILs, such as alkylimidazolium chlorides, tetrafluoroborates and hexafluorophosphates, were used to activate sulfur vulcanization of EPDM filled with CB. The effect of ILs structure, thus the length of alkyl chain bonded to the imidazolium cation and the type of anion, on the vulcanization parameters, thermal stability and dynamic mechanical properties of elastomeric composites was studied using different techniques of thermal analysis.

ILs significantly reduced the onset temperature and enthalpy of EPDM vulcanization. The most active were alkylimidazolium chlorides, which eliminated the post- curing process. The activity of ILs in the vulcanization process decreased with increasing length of the alkyl chain bonded to the imidazolium ring of the IL cation, so with reducing the molar content of IL in the rubber compound. As a result, higher onset vulcanization temperatures and lower enthalpies of vulcanization were achieved for rubber compounds with long-chain ILs.

The structure of ILs, especially the anion, significantly affected the thermal stability of EPDM. ILs decreased the onset decomposition temperature of vulcanizates. The largest reduction of $T_{5 \%}$ temperature was achieved for EPDM containing alkylimidazolium chlorides, whereas the smallest was achieved for hexafluorophosphates due to the lower stability of ILs, the decomposition of which preceded the pyrolysis of elastomer. The lower the thermal stability of pure IL was, the greater the reduction in onset decomposition temperature of EPDM vulcanizates was. No less important was the molar content of IL in the rubber compounds. The lowest $T_{5 \%}$ temperatures were achieved for vulcanizates with the highest molar content of IL. Onset decomposition temperature of pure ILs increased with the length of the alkyl chain in the imidazolium cation and was the lowest for ILs with the chloride anion.

Regarding the mechanical properties of EPDM under dynamic conditions, the more important influence seemed to be the type of IL anion. ILs influenced the storage modulus in a glassy state, but in the rubbery elastic region, their effect was much less pronounced. Vulcanizates with alkylimidazolium chlorides showed a storage modulus 
Table 6 Storage modulus $E^{\prime}$, glass transition temperature $T_{\mathrm{g}}$ and mechanical loss factor $\tan \delta$ of EPDM vulcanizates in the glassy state $\left(-80{ }^{\circ} \mathrm{C}\right)$ and rubbery elastic region $\left(25^{\circ} \mathrm{C}\right.$ and $\left.60{ }^{\circ} \mathrm{C}\right)$

\begin{tabular}{|c|c|c|c|c|c|c|c|}
\hline EPDM composites & $E_{\left(-80{ }^{\circ} \mathrm{C}\right)}^{\prime} / \mathrm{MPa}$ & $E_{\left(25^{\circ} \mathrm{C}\right)}^{\prime} / \mathrm{MPa}$ & $E_{\left(60{ }^{\circ} \mathrm{C}\right)}^{\prime} / \mathrm{MPa}$ & $T_{\mathrm{g}} /{ }^{\circ} \mathrm{C}$ & $\operatorname{Tan} \delta_{(T \mathrm{~g})} /-$ & $\operatorname{Tan} \delta_{\left(25{ }^{\circ} \mathrm{C}\right)} /-$ & $\overline{\left.\operatorname{Tan} \delta_{(60}{ }^{\circ} \mathrm{C}\right)} /-$ \\
\hline $\mathrm{ZnO}$ & 2134 & 10 & 10 & -59 & 0.85 & 0.06 & 0.04 \\
\hline \multicolumn{8}{|l|}{ Chlorides } \\
\hline $\mathrm{EmiCl}$ & 2116 & 8 & 8 & -60 & 0.88 & 0.07 & 0.05 \\
\hline $\mathrm{BmiCl}$ & 2034 & 6 & 7 & -59 & 0.94 & 0.06 & 0.05 \\
\hline $\mathrm{HmiCl}$ & 2018 & 8 & 9 & -61 & 0.88 & 0.07 & 0.05 \\
\hline $\mathrm{OmiCl}$ & 2154 & 9 & 9 & -62 & 0.85 & 0.06 & 0.04 \\
\hline \multicolumn{8}{|l|}{ Tetrafluoroborates } \\
\hline $\mathrm{EmiBF}_{4}$ & 1994 & 11 & 11 & -59 & 0.75 & 0.05 & 0.04 \\
\hline $\mathrm{BmiBF}_{4}$ & 2233 & 11 & 11 & -60 & 0.84 & 0.06 & 0.04 \\
\hline $\mathrm{HmiBF}_{4}$ & 2258 & 8 & 8 & -59 & 1.05 & 0.05 & 0.04 \\
\hline $\mathrm{OmiBF}_{4}$ & 2430 & 8 & 9 & -59 & 1.09 & 0.05 & 0.03 \\
\hline \multicolumn{8}{|c|}{ Hexafluorophosphates } \\
\hline $\mathrm{EmiPF}_{6}$ & 2304 & 8 & 9 & -59 & 0.98 & 0.05 & 0.03 \\
\hline $\mathrm{BmiPF}_{6}$ & 2522 & 12 & 13 & -59 & 1.00 & 0.05 & 0.04 \\
\hline $\mathrm{HmiPF}_{6}$ & 2399 & 10 & 10 & -59 & 0.99 & 0.05 & 0.04 \\
\hline $\mathrm{OmiPF}_{6}$ & 2327 & 7 & 8 & -59 & 1.03 & 0.04 & 0.03 \\
\hline
\end{tabular}

Standard deviation of $T_{\mathrm{g}} \pm 1{ }^{\circ} \mathrm{C}, \tan \delta \pm 0.03, E^{\prime}{ }_{\left(-80{ }^{\circ} \mathrm{C}\right)} \pm 167 \mathrm{MPa}, E^{\prime}\left(25{ }^{\circ} \mathrm{C}, 60^{\circ} \mathrm{C}\right) \pm 2 \mathrm{MPa}$

slightly lower or comparable to that of EPDM without ionic liquid in the glassy state, whereas vulcanizates containing ILs with $\mathrm{BF}_{4}$ and $\mathrm{PF}_{6}$ anions exhibited approximately 100-300 MPa higher storage modulus than the reference vulcanizate. ILs did not significantly affect the $T_{\mathrm{g}}$ of EPDM. The highest loss factor at $T_{\mathrm{g}}$ exhibited vulcanizates containing hexafluorophosphates and long-chain tetrafluoroborates, so with the lowest molar content of IL. On the other hand, ILs had no significant influence on the loss factor or damping properties of EPDM in the rubbery elastic region. Vulcanizates containing ILs exhibited stable dynamic properties at the temperatures of use. The storage modulus and mechanical loss factor did not change considerably in the temperature range of $25-60{ }^{\circ} \mathrm{C}$.

Funding This work was supported by the French companies Hutchinson S.A. and Total S.A.

\section{Compliance with ethical standards}

Conflict of interest The authors declare that they have no conflict of interest.

Informed consent Informed consent was obtained from all individual participants included in the study.

Open Access This article is distributed under the terms of the Creative Commons Attribution 4.0 International License (http://creative commons.org/licenses/by/4.0/), which permits unrestricted use, distribution, and reproduction in any medium, provided you give appropriate credit to the original author(s) and the source, provide a link to the Creative Commons license, and indicate if changes were made.

\section{References}

1. Kruzelak J, Sykora R, Hudec I. Vulcanization of rubber compounds with peroxide curing systems. Rubber Chem Technol. 2017;90:60-88.

2. Kruzelak J, Sykora R, Hudec I. Sulphur and peroxide vulcanisation of rubber compounds-overview. Chem Papers. 2016;70:1533-55.

3. Blow CM, Hepburn C. Rubber technology and manufacture. 2nd ed. London: Butterworth Scientific; 1981.

4. Coran AY. Vulcanization. In: Mark JE, Erman B, Eirich R, editors. The science and technology of rubber. San Diego: Academic Press; 1994. p. 337-81.

5. Cowie MG. Polymers: chemistry and physics of modern materials. 2nd ed. Cheltenharm: Stanley Thornes; 1998.

6. Abi Santhosh A, Kuruvilla J, Thomas M, Volker A, Sabu T. Studies on accelerated sulphur vulcanization of natural rubber using 1-phenyl-2,4-dithiobiuret/tertiary butyl benzothiazole sulphenamide. Eur Polym J. 2003;39:1451-60.

7. Heideman G, Noordermeer JWM, Datta RN, Van Baarle B. Effect of zinc complexes as activator for sulfur vulcanization in various rubbers. Rubber Chem Technol. 2005;78:245-57.

8. Heideman G, Datta RN, Noordermeer JWM, Van Baarle B. Multifunctional additives as zinc-free curatives for sulfur vulcanization. Rubber Chem Technol. 2006;79:561-88.

9. Coran AY. Chemistry of the vulcanization and protection of elastomers: a review of the achievements. J Appl Polym Sci. 2003;87:24-30. 
10. Akiba M, Hashim AS. Vulcanization and crosslinking in elastomers. Prog Polym Sci. 1997;22:475-521.

11. Donnet JB, Custodero E. Reinforcement of elastomers by particulate fillers. In: Mark JE, Erman B, Eirich FR, editors. Science and technology of rubber. Cambridge: Academic Press; 2005. p. 383-415.

12. Mark JE, Erman B, Eirich FR. Science and technology of rubber. 1st ed. San Diego: Academic Press; 1994.

13. Joseph AM, George B, Madhusoosaban KN, Alex R. Current status of sulphur vulcanization and devulcanization chemistry: process of vulcanization. Rubber Sci. 2015;28:82-121.

14. Chapman A, Johnson T. The role of zinc in the vulcanization of styrene-butadiene rubbers. Kautsch Gummi Kunst. 2005;58: 358-61.

15. Przybyszewska M, Zaborski M, Zawadiak J, Jakubowski B. Zinc chelates as new activators for sulphur vulcanization of acrylonitrile-butadiene rubber. eXPRESS Polym Lett. 2009;3:256-66.

16. Maciejewska M, Zaborski M. Ionic liquids as coagents for sulfur vulcanization of butadiene-styrene elastomer filled with carbon black. Polym Bull. 2018;75:4499-514.

17. Xu P, Gui HG, Hu YD, Bahader A, Ding YS. Dielectric properties of polypropylene-based nanocomposites with ionic liquidfunctionalized multiwalled carbon nanotubes. J Electron Mater. 2014;43:2754-8.

18. Lei YD, Tang ZH, Guo BC, Zhu LX, Jia DM. Synthesis of novel functional liquid and its application as a modifier in SBR/silica composites. eXPRESS Polym Lett. 2010;4:692-703.

19. Kreyenschulte H, Richter S, Götze T, Fischer D, Steinhauser D, Klüppel M, Heinrich G. Interaction of 1-allyl-3-methylimidazolium chloride and carbon black and its influence on carbon black filled rubbers. Carbon. 2012;50:3649-58.

20. Galiński M, Lewandowski A, Stępniak I. Ionic liquids as electrolytes. Electrochim Acta. 2006;51:5567-80.

21. Kubisa P. Perspectives of ionic liquids' applications in polymer chemistry. Polimery. 2006;7:485-90.

22. Ning W, Xingxiang Z, Haihui L, Benqiao H. 1-Allyl-3methylimidazolium chloride plasticized-corn starch as solid biopolymer electrolytes. Carbohyd Polym. 2009;76:482-4.

23. Wang P, Zakeeruddin SM, Moser JE, Gratzel M. New ionic liquid electrolyte enhances the conversion efficiency of dyesensitized solar cells. J Phys Chem B. 2003;107:13280-5.

24. Kawano R, Matsui H, Matsuyama Ch, Sato A, Susan MABH, Tanabe N, Watanabe M. High performance dye-sensitized solar cells using ionic liquids as their electrolytes. J Photochem Photobiol A. 2004;164:87-92.

25. Parvulescu VI, Hardacre C. Catalysis in ionic liquids. Chem Rev. 2007; 107:2615-65.

26. Harrison S, MacKenzie SR, Haddleton DM. Unprecedented solvent-induced acceleration of free-radical propagation of methyl methacrylate in ionic liquids. Chem Commun. 2002;1:2850-1.

27. Shen Y, Tang H, Ding S. Catalyst separation in atom transfer radical polymerization. Prog Polym Sci. 2004;29:1053-78.

28. Wang YY, Li W, Dai Y. Cationic ring-opening polymerization of 3,3- bis(chloromethyl)oxacyclobutane in ionic liquids. Chin Chem Lett. 2007;18(1187):90.
29. Yang Y, Tsai YT. Inhibition ability of ionic liquid $[\mathrm{Bmim}]\left[\mathrm{NO}_{3}\right]$, $[\mathrm{Bmim}]\left[\mathrm{BF}_{4}\right]$, and $[\mathrm{Emim}]\left[\mathrm{BF}_{4}\right]$ on spontaneous coal combustion. J Therm Anal Calorim. 2018;132:1943-51.

30. Nockemann P, Thijs B, Pittois S, Thoen J, Glorieux C, van Hecke $\mathrm{K}$, van Meervelt L, Kirchner B, Binnemans K. Task-specific ionic liquid for solubilizing metal oxides. J Phys Chem B. 2006;110: 20978-92.

31. Nockemann P, Thijs B, Parac-Vogt TN, van Hecke K, van Meervelt L, Tinant B, Hartenbach I, Schleid T, Ngan VT, Nguyen MT. Carboxyl-functionalized task-specific ionic liquids for solubilizing metal oxides. Inorg Chem. 2008;47:9987-99.

32. Wellens S, Vander Hoogerstraete T, Möller C, Thijs B, Luyten J, Binnemans K. Dissolution of metal oxides in an acid-saturated ionic liquid solution and investigation of the back-extraction behaviour to the aqueous phase. Hydrometallurgy. 2014;144-145: 27-33.

33. Maciejewska M, Zaborski M. Thermal analysis and mechanical methods applied to studying properties of SBR compounds containing ionic liquids. Polym Test. 2017;61:349-63.

34. Lu J, Yan F, Texter J. Advanced applications of ionic liquids in polymer science. Prog Polym Sci. 2009;34:431-48.

35. Subramaniam K, Das A, Häußler L, Harnisch C, Stöckelhuber KW, Heinrich G. Enhanced thermal stability of polychloroprene rubber composites with ionic liquid modified MWCNTs. Polym Degrad Stab. 2012;97:776-85.

36. Wagner M. Thermal analysis in practice. Collected applications. Schwarzenbach: Mettler Toledo; 2009.

37. Simon P, Kucma A. DSC analysis of the induction period in the vulcanisation of rubber compounds. J Therm Anal Calorim. 1999;56:1107-13.

38. Prochon M, Janowska G, Przepiorkowska A, Kucharska-Jastrzabek A. Thermal properties and combustibility of elastomerprotein composites Part I. Composites SBR-keratin. J Therm Anal Calorim. 2012;109:1563-70.

39. Manaila E, Stelescu MD, Craciun G. Aspects regarding radiation crosslinking of elastomers. In: Boczkowska A, editor. Advanced elastomers. London: IntechOpen Limited; 2012. p. 3-34.

40. Janowska G, Slusarski L. Thermal properties of cis-1,4poly(butadiene). J Therm Anal Calorim. 2001;65:205-12.

41. Ngo HL, LeCompte K, Hargens L, McEwen AB. Thermal properties of imidazolium ionic liquids. Thermochim Acta. 2000;357(358):97-102.

42. Lemos MF, Bohn MA. DMA of polyester-based polyurethane elastomers for composite rocket propellants containing different energetic plasticizers. J Therm Anal Calorim. 2018;131:595-600.

43. Das A, Stöckelhuber KW, Jurk R, Fritzche J, Klüppel M, Heinrich $\mathrm{G}$. Coupling activity of ionic liquids between diene elastomer and multiwalled carbon nanotubes. Carbon. 2009;47:3313-21.

44. Xu P, Wang X, Hu Y, Ding Y. Piezoresistive properties of nanocomposites based on silicone rubber and ionic liquid-functionalized carbon black. Mater Lett. 2016;182:218-22.

Publisher's Note Springer Nature remains neutral with regard to jurisdictional claims in published maps and institutional affiliations. 